\title{
ESTUDOS PRELIMINARES DE UMA LECTINA DE SEMENTES DE PARKIA PLATYCEPHALA BENTH.
}

Grangeiro, T.B. ${ }^{2}$

De Oliveira. J.T.A.'

Moreira, R.A.'

Cavada, B.S.'

\begin{abstract}
RESUMO - Sementes de Parkia platycephala Benth.possuem uma lectina que é melhor extraída a $\mathrm{pH} 4,0$ e pode ser isolada por cromatografia de afinidade em coluna de Sephadex G-50. A lectina aglutina eritrócitos de coelho mas não aglutina hemácias humanas (A, B e O), de boi, de carneiro ou de galinha. D-glicose, D-manose, $\mathrm{D}$-frutose e derivados mostraram ser açúcares inibidores da atividade hemaglutinante, sendo que alfa-metil-glicosídeo e alfa-metil-manosídeo foram os mais potentes inibidores entre os açúcares testados.
\end{abstract}

Palavra-chave: Lectina, Parkia platycephala.

ABSTRACT - Seeds of Parkia platycephala Benth. have a lectin which is best extracted at $\mathrm{pH} \mathrm{4,0}$ and partially purified using a Séphadex G-50 column as an affinity adsorbent. The lectin -agglutinates rabbit erythrocytes but not those of cow, sheep, chicken or human D-glucose, D-mannose, D-fructose and derivatives act as inhibitors of the lectin with o-methyl-glucopyranoside and $\mathrm{O}$-methyl-mannopyranoside being the most potent ones.

Key words: Lectin, Parkia platycephala.

\section{Introdução}

Lectinas são proteínas, ou glicoproteínas, que possuem a capacidade de aglutinar eritrócitos e outros tipos de células. Apesar de sua ampla distribuição na natureza, as lectinas são encontradas principalmente em sementes de plantas e, em menor quantidade, em raízes, folhas e caules (Sharon \& Lis, 1972). As sementes de leguminosas têm se mostrado uma excelente fonte de lectinas,

1 - Departamento de Bioquímica Molecular Centro de Ciências, Universidade Federal do Ceará, Caixa Postal 1065-60.001 - Fortaleza - CE.

2 - Bolsista de iniciação científica do CNPq. 
as quais chegam a constituir, em alguns casos, mais de $10 \%$ das proteínas solúveis presentes no extrato de sementes maduras. Dentro da família Leguminoseae, as lectinas constituem uma classe bastante homogênea de proteínas, o que sugere que as mesmas foram conservadas durante o processo de evolução das espécies pertencentes a esta família, como também reflete o grau de relacionamento taxonômico entre as mesmas (Etzler, 1985, Rougé et al, 1987). No presente trabalho são apresentados alguns dados preliminares referentes ao isolamento de uma lectina de sementes de Parkia platycephala Benth, leguminosa mimosoidea.

\section{Material e métodos}

Material vegetal.

As sementes de Parkia platycephala Benth. foram coletadas no município de Granja, Estado do Ceará, Brasil. Extração de proteínas. A farinha de sementes descorticadas de Parkia platycephala foi colocada para extrair, numa relação $1: 10(\mathrm{p} / \mathrm{v})$, com tampão acetato de sódio $0,2 \mathrm{M}, \mathrm{pH} \mathrm{4,0}$ contendo $\mathrm{NaCl}$ $0,15 \mathrm{M}$, durante 12 horas, após o que foi centrifugada a $15.000 \mathrm{~g}$, por $20 \mathrm{minu}$ tos a $4^{\circ} \mathrm{C}$. $\mathrm{O}$ extrato total obtido foi utilizado nas determinações posteriores.

\section{Dosagem de proteínas}

A determinação de proteínas nos diferentes extratos foi realizada segundo o método de Bradford (1976), utilizando-se albumina sérica bovina como padrão. A absorbância a $280 \mathrm{~nm}$ foi utilizada para dosar proteínas em eluatos cromatográficos.

Atividade hemaglutinante.

A atividade hemaglutinante no extrato total e nas frações foi determinada segundo o método descrito por Moreira \& Perrone (1977), usando-se uma suspensão a $2 \%$ de hemácias humanas (A, B e O) e de vários animais. A atividade hemaglutinante específica foi expressa como unidade de hemaglutinação (U.H.) $\mathrm{mg}^{-1}$. Uma U.H. foi estabelecida como a concentração de proteínas por $\mathrm{ml}$ no último tubo que apresentou hemaglutinação visível.

\section{Inibição da Atividade Hemaglutinante por Açúcares}

Soluções de diferentes açúcares $(0,25 \mathrm{ml})$ na concentração inicial de $1 \mathrm{M}$, foram submetidas a diluições seriadas 1:2 e, posteriormente, a cada diluição 
Tabela 1 - Especificidade por Hemácias do Extrato Total de Parkia platycephala Benth.

\begin{tabular}{lcc}
\hline Hemácias $(2 \%)$ & Título (U.H./ml) \\
\hline Coelho & 32 \\
Boi & - \\
Cabra & - \\
Ovelha & - \\
Galinha & A & - \\
Humano & B & - \\
& O & - \\
& & - \\
\hline
\end{tabular}

Tabela 2 - Ensaio de Inibição da Atividade Hemaglutinante do Extrato Total de Parkia platycephala Benth. por Açúcares.

Açúcar (1M)

Concentração Mínima

Para Inibir

$1 \mathrm{UH}(\mathrm{mM})$

Arabinose

Frutose

NI*

Galactose

31,25

Glucose

NI

Alfa-Metil-Glucosídeo

125,0

Lactose

15,62

Manose

Alfa-Metil-Manosídeo

NI

Rafinose

15,62

15,62

Ramnose

NI

Sacarose

NI

Xilose

250,0

NI

* NI - Não Inibiu 


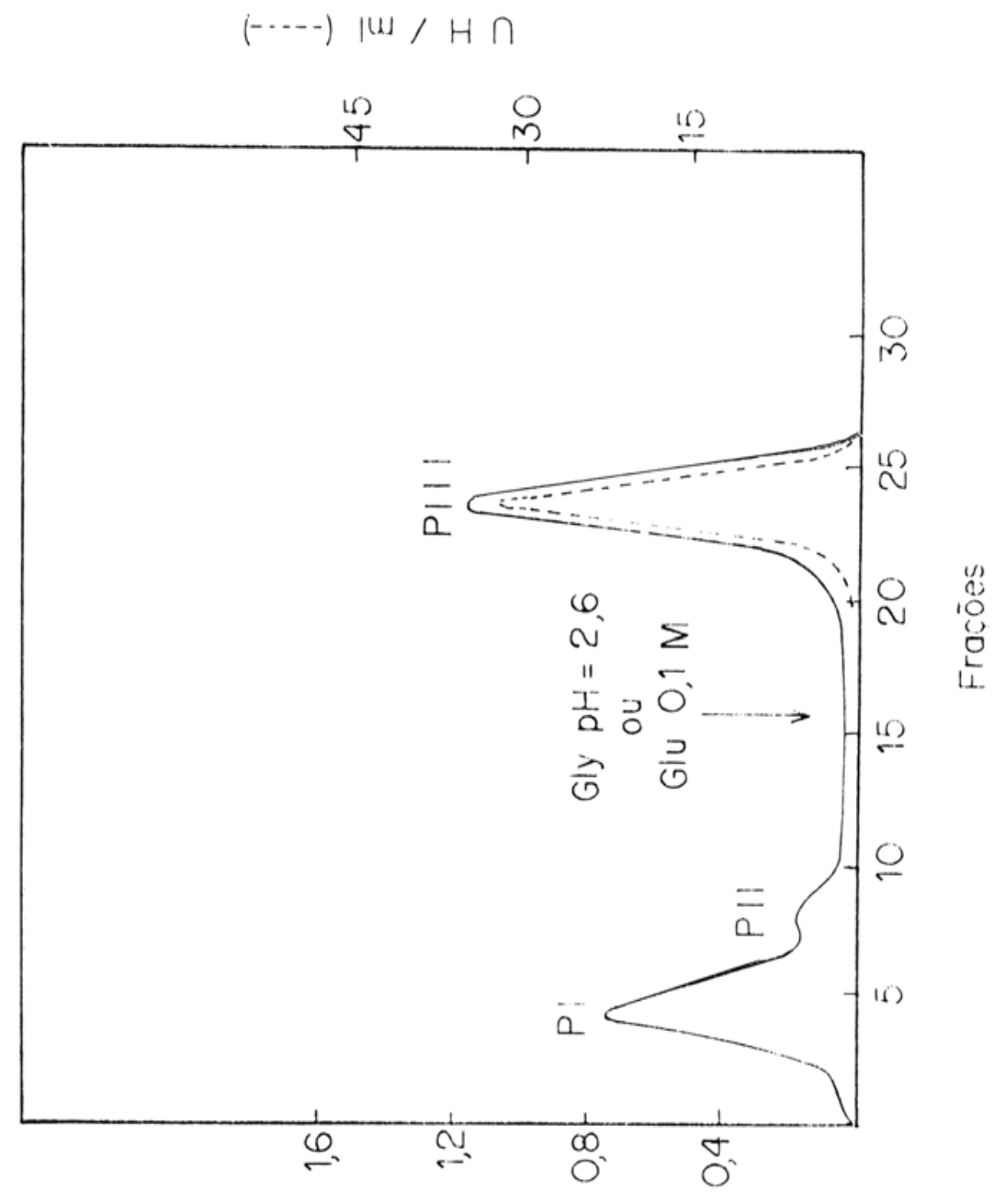

$(-) 082 \mathrm{~V}$

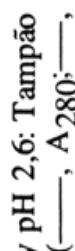

心

उ०

รี ั

응

항

응을

뽄

ए०

인

ฐึำ

음

可

ㅊ.

은

$00^{\circ}$

는

离玄

ชั

꽁응

톤

08

뭉

可

$\approx \Sigma$

웅

เั็

韸

约资

놀

is 
adicionou-se extrato total $(0,25 \mathrm{ml})$ a uma diluição correspondente ao dobro da unidade de hemaglutinação, determinada previamente. As amostras diluídas foram colocadas na estufa a $37^{\circ} \mathrm{C}$ por 30 minutos, $0,5 \mathrm{ml}$ de solução de hemácias a $2 \%$ foi então adicionado a cada uma, e o título de hemaglutinação foi determinado.

\section{Cromatografia de Afinidade em Coluna de Sephadex G-50}

O extrato total foi aplicado em uma coluna de Sephadex G-50 equilibrada com $\mathrm{NaCl} 0,15 \mathrm{M}$ contendo $\mathrm{Ca}++\mathrm{e} \mathrm{Mn}++5 \mathrm{mM}$. A eluição foi feita com a solução de equilíbrio seguido da mesma solução contendo Glicose $0,1 \mathrm{M}$.

\section{Resultados e discussão}

O extrato total a pH 4,0 de farinha de sementes de Parkia platycephala, previamente determinado como sendo a melhor condição de extração, quando submetido a ensaio de hemaglutinação frente a hemácias humanas e de vários animais, apresentou os resultados sumarizados na Tabela 1. Nenhuma atividade hemaglutinante foi detectada com relação a hemácias humanas (A, B e O) e no caso de hemácias de animais, o extrato total aglutinou somente hemácias de coelho, sendo incapaz de aglutinar hemácias de boi, cabra, ovelha e galinha. A atividade hemaglutinante presente no extrato total e detectada com o uso de hemácias de coelho foi inibida por glucose, manose, frutose e seus derivados (Tabela 2). Estes resultados permitem classificar os açúcares inibidores da lectina presente neste extrato como pertencentes ao grupo 3 de Mäkela (Mäkela, 1957). Em função dos resultados obtidos com a inibição da atividade hemaglutinante por açúcares, o extrato total foi aplicado a uma coluna de Sephadex G-50 (Figura 1), onde obteve-se a fração ativa PIII (lectina), que contém toda a atividade hemaglutinante, perfazendo $67,8 \%$ da proteína total aplicada à coluna.

\section{Referência bibliográficas}

BRADFORD, M.M. 1976. A rapid and sensitive method for the quantitation of microgram quantities of protein utilizing the principle of protein-dye binding. Anal. Biochem. 72:248-254.

ETZLER, M.E. 1985. Plant Lections: Molecular and Biological Aspects. Ann. Rev. Plant. Physiol. 36:209-34.

MÄKELA, O. 1957. 'Studies on Hemagglutinins of Leguminosae Seeds'. 
Weilin \& Goos, Helsink.

MOREIRA, R.A. \& J.C. PERRONE, 1977. Purification and partial characterization of lectin from Phaseolus vulgaris. Plant Physiol. 59:783-787.

ROUGÉ, P., M. RICHARDSON, A. YARWOOD \& B.S. CAVADA, 1987. Single and two chair legume lectins as phylogenetic markers of speciation. Biochem. System. Ecol. 15:341-348.

SHARON, N., \& H. LIS, 1972. Lectins: Cell-Agglutining and Sugar-Specific Proteins. Science. 177 (4053):951-959. 